\title{
Catalytic antibodies: Regio- and enantioselectivity in a hetero Diels-Alder reaction
}

\author{
Marina Resmini, Arthur A.P. Meekel and Upendra K. Pandit* \\ Laboratory of Organic Chemistry, University of Amsterdam, \\ Nieuwe Achtergracht 129, 1018 WS Amsterdam, The Netherlands
}

\begin{abstract}
Antibodies were generated against a bicyclic transition state analogue of the Diels-Alder reaction between piperylene and an arylnitroso dienophile. One of the antibodies (309-1G7) showed a good rate enhancement of the reaction between cis-piperylene and 4-nitroso- $N$-propyl-benzamide, with a $k_{\text {cat }} / k_{\text {uncat }}=2618$.

More significantly, the same antibody showed excellent regioselectivity $(>95 \%)$, by steering the reaction towards the formation of the targeted product. Finally, studies on the enantioselectivity of the catalysed reaction demonstrated that the formation of this product proceeds with an e.e. of $82 \%$. Moreover, addition of the free hapten completely inhibited all activity of the antibody, demonstrating that the reaction takes place within the active site of the antibody.
\end{abstract}

The concept of using transition state analogues to elicit catalytic antibodies has been applied successfully to a variety of chemical transformations, yielding, in some cases, antibodies with remarkable catalytic and stereoselective properties (1). The development of catalytic antibodies for the Diels-Alder reaction has received great impetus in view of its widespread application in organic synthesis (2), and because of the fact that no natural enzymes are known which can affect the course of this cyclization process. However, very recently, experimental evidence has been presented which indicates DielsAlderase activity in a crude cell-free extract from the fungus Alternaria solani (3).

In view of the fact that several examples of the carbocyclic version of the Diels-Alder reaction involving antibody-mediated catalysis have been reported in recent years (4), work in this laboratory has been specifically directed towards generating antibody catalysts for a hetero Diels-Alder reaction. Very recently, we have reported on the antibody-mediated catalysis of the cycloaddition of trans-piperylene 1 to 4-nitroso- $N$-propyl-benzamide $\underline{2}$ (Fig. 1) (5). We now wish to communicate our results on the regioand enantioselective catalysis of the hetero Diels-Alder reaction between cis-piperylene 5 and dienophile $\underline{2}$, under influence of antibody 309-1G7, which was raised against hapten $\underline{6}$ (Fig. 2a). Three features of this reaction may be noted: (i) the reaction leads to the formation of only two regioisomeric products, namely 3 and 4 , since the hetero atoms of the dienophile avoid the generation of endo and exo adducts; (ii) the presence of the methyl group in the diene allows an examination of the regioselectivity of the antibody active site; hapten $\underline{6}$, it may be emphasised, was specifically designed to propagate the formation of isomer 4; (iii) the methyl substituent introduces an asymmetric centre in the product, thereby offering an opportunity for evaluating the enantioselective character of the antibody-catalysed process.

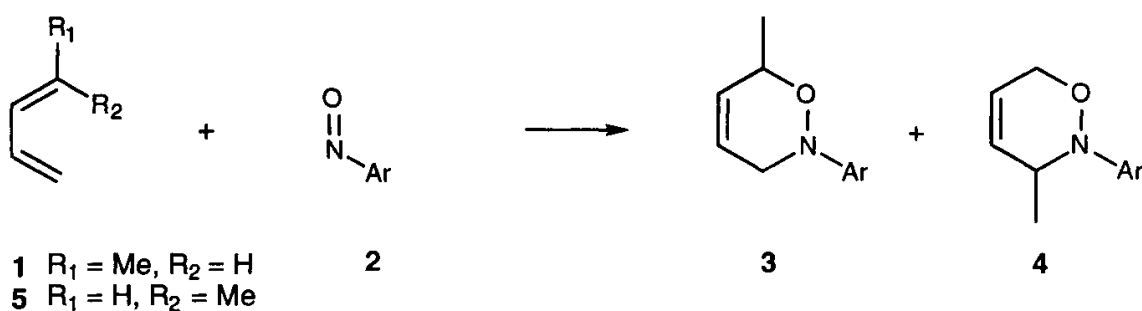

Fig. 1 Hetero Diels-Alder reaction under study; $\mathrm{Ar}=p-\mathrm{C}_{6} \mathrm{H}_{4} \mathrm{CONHPr}$ 
The synthesis of hapten $\underline{6}$ and the generation of antibody 309-1G7 has been described earlier (5). It was shown previously that antibody 309-1G7 enhanced the rate of the reaction between trans-piperylene $\underline{1}$ and dienophile $\underline{2}$ and also moderately steered the reaction in favour of the targeted product $\underline{4}$. The reaction between cis-piperylene $\underline{5}$ and dienophile $\underline{2}$ under the influence of antibody 309-1G7 was studied employing the same experimental conditions (6). The rates of the reactions were measured by following the decrease in absorbance of the dienophile $\underline{2}$ at $340 \mathrm{~nm}$. The pseudo first order rate constant for the uncatalysed reaction ( $k_{\text {uncat }}$ ) was found to be $7.010^{-5} \mathrm{~s}^{-1}$. The activity of 309-1G7 was determined as a function of the concentration of dienophile 2 , by measuring initial rates of the catalysed reactions, within $5 \%$ completion. The data obtained were corrected for the background reaction (7) and employed to construct a Lineweaver-Burk plot (Fig. 3). The results gave a $K_{M}$ value for the dienophile 2 of $3.94 \mathrm{mM}$, $V_{\max }$,app. of $1.7410^{-3} \mathrm{mM} \mathrm{s}^{-1}$ and $k_{\mathrm{cat}}$,app of $1.8310^{-1} \mathrm{~s}^{-1}$, which afforded a value of $k_{\mathrm{cat}} / k_{\text {uncat }}$ of 2618. Upon fitting the kinetic data to the hyperbolic form of the Michaelis Menten equation comparable results were obtained.

a)

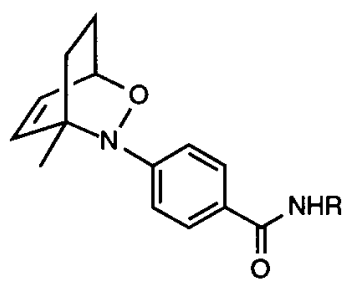

$6 \mathrm{R}=\left(\mathrm{CH}_{2}\right)_{5} \mathrm{CO}_{2} \mathrm{H}$

$7 \mathrm{R}=\mathrm{CH}_{2} \mathrm{CH}_{2} \mathrm{CH}_{3}$

b)

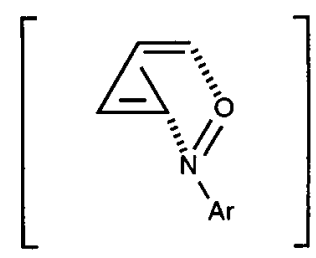

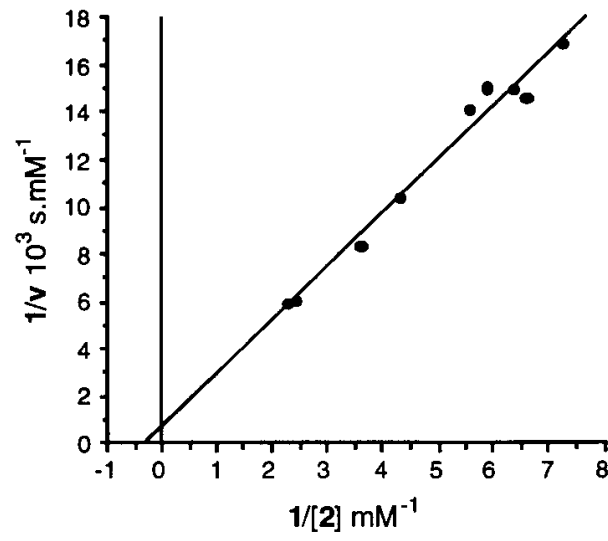

Fig. 3 Lineweaver-Burk plot for the reaction of diene $\underline{5}$ with dienophile $\underline{2}$ catalysed by $309-1 \mathrm{G} 7$.
Fig. 2 (a) Structures of hapten 6 and inhibitor 7 . (b) Boat-like transition state for the reaction of diene $\underline{5}$ and dienophile $\underline{2}$.

The higher activity of 309-1G7 in the reaction with cis-diene 5, compared to our earlier findings with trans-diene 1 , implies that the transition state for the reaction between 5 and 2 is better mimicked by hapten $\underline{6}$. This transition state is boat-like in its stereochemistry and bears the methyl substituent in an pseudo-axial position (Fig. $2 b$ ). Presumably, the ethano bridge and the methyl group hapten $\underline{6}$ induce a hydrophobic region in the antibody active-site, which not only stabilises the transition state originating from the reaction with cis-diene 5 but also induces the preferential formation of regioisomer 4 .

The product distribution of the regioisomers $\underline{3}$ and $\underline{4}$ in the reactions was determined by analytical reverse phase HPLC (8). The uncatalysed reaction showed a ratio between adducts 3 and 4 of $48: 52$. The antibody 309-1G7 exercised a remarkable influence on the regioselectivity of the cycloaddition. In the presence of $10 \%$ of $309-1 \mathrm{G} 7$, related to [2], the aforementioned ratio shifted to $32: 68$, revealing an increase in the formation of the amount of product 4 . Even more significantly, when the reaction was carried out using equimolar amounts of dienophile $\underline{2}$ and 309-1G7, product $\underline{4}$ was obtained almost exclusively, with less than $5 \%$ of 3 being present in the reaction mixture. The latter experiment was performed in order to avoid product inhibition and to minimise the effects of the background reaction. 
The highly regioselective formation of $\underline{4}$ in the equimolar reaction implies that when a stoichiometric amount of the catalyst is employed, almost the entire reaction proceeds within the active site of the antibody.

The selectivity dictated by $309-1 \mathrm{G} 7$ in the formation of the targeted regioisomer prompted us to investigate the enantioselectivity of the catalysed reaction. In order to determine this, the products of the reaction were isolated and analysed by capillary electrophoresis $(9,10)$. When an equimolar amount of 309-1G7 was employed in the reaction and following $100 \%$ conversion of dienophile 2 , the product 4 formed showed an enantiomeric excess of $82 \%$, after correction for the background reaction. The absolute stereochemistry of the major enantiomer of $\underline{4}$ is not known at present and remains to be established.

Addition of equimolar amounts of the free hapten 7 (Fig. 2a) to the catalysed reaction completely inhibited the activity of the antibody with respect to rate enhancement, regio- and enantioselectivity. The background reaction was unaffected by addition of non-specific protein (BSA) or normal mouse IgG.

The enhancement of the reaction rate, the regioselectivity and the enantioselectivity, which is mediated by a specifically delineated antibody, demonstrates the merits and potential of antibody catalysts in synthetic organic chemistry. It may be projected that this class of highly specific catalysts which can be truly considered as designed and developed on a rational basis - may find important applications, amongst other areas, in the field of synthesis of fine chemicals.

\section{Acknowledgements}

This work was conducted in part under auspices of the Stichting Scheikundig Onderzoek Nederland (S.O.N.) and the European Network on Antibody Catalysis. Financial support of the Netherlands Organisation of Scientific Research (N.W.O.) to A.A.P.M. and of the European Community Human Capital and Mobility Programme to M.R. is gratefully acknowledged. We wish to thank Professor H. Poppe of the Analytical Chemistry Department, University of Amsterdam, for helpful discussions on the application of capillary electrophoresis and Mr. Henk Vonk for performing the electrophoresis experiments.

\section{References}

1. (a) R. A. Lerner, S. J. Benkovic and P. G. Schultz, Science 252, 659-667 (1991). (b) A. Koch, J.L. Reymond and R. A. Lerner, J. Am. Chem. Soc. 116, 803-804 (1994). (c) U. K. Pandit, Recl. Trav. Chim. Pays-Bas 112, 431-443 (1993).

2. (a) D. L. Boger and S. M. Weinreb, Hetero Diels-Alder Methodology in Organic Synthesis, Academic Press, London (1987). (b) H. B. Kagan and O. Riant, Chem. Rev., 1007-1019 (1992). (c) J. Streith and A. Defoin, Synthesis, 1107-1117 (1994).

3. H. Oikawa, K. Katayama, Y. Suzuki and A. Ichihara, J. Chem. Soc., Chem. Commun., 1321-1322, (1995).

4. (a) D. Hilvert, K. W. Hill, K. D. Nared and M.-T. M. Auditor, J. Am. Chem. Soc. 111, 9261-9262 (1989). (b) A. C. Braisted and P. G. Schultz, J. Am. Chem. Soc. 112, 7430-7431 (1990). (c) C. J. Suckling, M. C. Tetford, L. M. Bence, J. I. Irvine and W. H. Stimson, J. Chem. Soc. Perkin Trans. 1, 1925-1929 (1993). (d) V. E. Gouverneur, K. N. Houk, B. de Pascual-Teresa, B. Beno, K. D. Janda and R. A. Lerner, Science 262, 204-208 (1993). (e) J. Yli-Kauhaluoma, J. A. Ashley, C.-H. Lo, L. Tucker, M. M. Wolfe and K. D. Janda, J. Am. Chem. Soc. 117, 7041-7047, (1995).

5. A. A. P. Meekel, M. Resmini and U. K. Pandit, J. Chem. Soc. Chem. Commun., 571-572 (1995).

6. Reactions were carried out under pseudo first order conditions in $10 \mathrm{mM} \mathrm{PBS}, 140 \mathrm{mM} \mathrm{NaCl}, \mathrm{pH}$ 7.3 containing $5 \%$ DMSO at room temperature; the concentration of diene 5 was held fixed at 5 $\mathrm{mM}$, the concentration of dienophile 2 varied from $0.1 \mathrm{mM}$ to $0.5 \mathrm{mM}$. Higher concentrations were not applied due to poor solubility of substrate $\underline{2}$. All catalyzed reactions were run with $9.5 \mu \mathrm{M}$ 
antibody 309-1G7. Antibody concentrations were determined by measuring the absorbance at 280 $\mathrm{nm}$, using $\varepsilon_{280}=202,5001 \mathrm{~mol}^{-1} \mathrm{~cm}^{-1}$ and a molecular weight of 150,000 . Sodium dodecyl sulphate polyacrylamide gel electrophoresis with Coomassie blue staining under reducing conditions, showed only heavy and light chains. Antibody 309-1G7 was characterized as $\operatorname{IgG}_{1}$ (K light chain).

7. The background reaction was run simultaneously with each antibody-catalyzed reaction, in order to ensure constant experimental conditions.

8. HPLC measurements were performed using a Polygosil $60 \mathrm{C} 18$ reverse-phase column, employing isocratic conditions: $\mathrm{MeOH} / \mathrm{H}_{2} \mathrm{O} 4: 6$ containing $0.1 \%$ TFA, $1.5 \mathrm{ml} / \mathrm{min}$, with UV detection at 282 $\mathrm{nm}$, retention time for substrate $\underline{2} 8.9 \mathrm{~min}$, for product $\underline{4} 28 \mathrm{~min}$ and for product $\underline{3} 31.5 \mathrm{~min}$. Data are uncorrected for the background reaction, which under these conditions is concurrently taking place.

9. To isolate the products, the antibody was denaturated by adding an equal volume of acetonitrile, the resulting suspension was centrifuged and the supernatant was evaporated to dryness. The residue was taken up in $\mathrm{CH}_{2} \mathrm{Cl}_{2}$, filtered and evaporated. Samples were analyzed using cyclodextrin-modified micellar electrokinetic chromatography. Conditions: capillary $90 \mathrm{~cm}(60 \mathrm{~cm}$ to the detector), $50 \mu \mathrm{m}$ internal diameter; separation solution: $50 \mathrm{mM}$ sodium deoxycholate in 6 $\mathrm{mM}$ borate buffer $\mathrm{pH} 9$ containing $35 \mathrm{mM} \alpha$-cyclodextrin, applied voltage $25 \mathrm{kV}$; UV detection at $282 \mathrm{~nm}$; retention times for the enantiomers of $428.7 \mathrm{~min}$ and $29.6 \mathrm{~min}$, for $331.1 \mathrm{~min}$. Under these conditions only the separation of the two enantiomers of 4 was achieved.

10. (a) S. Terabe, K. Otsuka and H. Nishi, J. Chromatogr. 666, 295-319 (1994). (b) S. Terabe, Y. Miyashita, Y. Ishihama and O. Shibata J. Chromatogr. 636, 47-55 (1993). (c) H. Nishi, T. Fukuyama and S. Terabe, J. Chromatogr. 553, 503-516 (1991). 